\title{
Writing Web page standards
}

\section{By Nancy McClements and Cheryl Becker}

\section{Establish content, design, and technical guidelines}

$\mathbf{T}$ he Problem. The University of Wisconsin-Madison is a large and diverse university campus, with more than 60 major libraries, special libraries, and reading rooms. Early in 1995 several campus libraries began developing Web pages which varied in design, style, and content. It soon became obvious that a level of standardization was necessary, and few written standards seemed to exist with our special needs-succinct instructions for staff of varying levels of expertise on a large, distributed campus. The person responsible for mounting the General Library System's homepage needed guidelines for the links he would make to other libraries. He turned to the User Documentation Working Group (UDWG) for assistance.

The Working Group. The UDWG is one of the several working groups that report to the Electronic Library Access Committee (ELAC), the public services arm of the campus libraries' electronic infrastructure. The UDWG's charge is to "define levels of online help and printed documentation necessary for user access to all library electronic resources. Develop guidelines for format and level of detail. Develop or coordinate the preparation of such help. Address ongoing updates to ensure currency." This fivemember group (Nancy McClements, Cheryl Becker, Patricia Herrling, Dennis Hill, and Don Johnson), which includes librarians and editorial staff from several campus libraries, agreed to work on this major project of developing campus standards for Web pages.
The Method. Existing standards and style sheets from the Web itself were examined, as were books such as Teach Yourself Web Publishing with HTML in a Week (Sams Publishing, 1995). We sought input from those who had developed local library homepages. The first draft took common themes from all these sources and organized them into one document. Sections soon emerged, as did those items that would be required as opposed to merely recommended. After going through several internal revisions, a draft was submitted to a larger audience via meetings, a public forum, and several group e-mail lists. All of these resulted in additional revisions. A final draft was approved in June 1995 by the Electronic Library Committee (ELC), the administrative arm of the campus libraries' electronic infrastructure

The Content. The document was mounted on the Web for easy access (http://www. library.wisc.edu/help/tech/Web_standards. html). Three sections make up the body: Content, Design, and Procedural/Technical. An appendix, made up of examples to illustrate most of the points, was distributed with the paper copy of the standards.

The Application. Authors of new Web pages must follow the required items in order to have their page linked to the main campus library homepage (http://www.library.wisc. edu). They are encouraged to employ the recommended items as well. To keep pages and links current, a standard reminder notice is sent to homepage developers at the beginning of each semester. The standards were written as a starting point. We intend to modify them as our needs change and as developments occur in Web technology. 


\section{Web Page Standards and Guidelines}

\section{University of Wisconsin-Madison Campus Libraries}

\section{Content}

\section{Required:}

1) On every homepage: name, address, and email address of responsible person or entity, for example, webadmin@libraryname.wisc.edu.

2) Date of last update for pages with substantive content.

3) Full name of unit (in title heading, document text, address, and/or graphical link) and/or URL in order that the source can be recoverable.

\section{Recommended:}

1) Copyright statement (if/when appropriate).

2) Statement of document status if in progress (for example, "prototype," "under construction")

3) "What's New" section on homepage.
4) Indication of restricted access where appropriate.

5) Warning statement if link will lead to large document or image.

6) No browser-specific terminology (for example, "pull down the File menu and select Save").

7) Link text should make sense even if link isn't present, as with a paper copy. For example, "To ask a reference question: askmemorial@ doit.wisc.edu," instead of "To ask a reference question, click here."

8) Use of a general style guideline (for example, Strunk \& White's Elements of Style).

9) Always think of your users-test with primary user groups.

\section{Design}

\section{Required:}

1) A link to the UW-Madison Electronic Library, including the gif icon, accessible by two or three direct jumps (clicks) from each document.

2) A link to return to the parent homepage ("Return to $\mathrm{xxx}$ Home Page") on all supporting local documents.

\section{Recommended:}

1) Style sheet (or template) to provide visual consistency across related documents.

2) Small graphic that identifies all of the documents of a Web site.

3) Short and simple homepage

4) Active links to mentioned documents.
5) No "monster" graphics; avoid many little graphics

6) Navigational aids useful to your users ("Return to Top," Table of Contents, Next/Previous Page for documents in a series, etc.).

7) "Hot buttons" for short cuts to most important links

8) Minimum text in lists or menus.

9) Logical tags used as intended instead of forcing them to serve as a graphical device (for example, use headings $<\mathrm{H} 1>$ as true headings, not just to achieve bold text).

10) Sparing use of bold, italics, blinking, etc.

11) Always think of your users - test with primary user groups.

\section{Procedural/technical}

\section{Required:}

1) A plan on how revisions will take place (schedule for updating, who will do, etc.). GLS Automation Services will e-mail a standard reminder notice to library homepage developers (via HTML-FOLKS) before each semester (fall, spring, and summer) to review and revise pages and to update links.

2) Test of links before mounting as well as a schedule for checking links and removing dead links.

3) Spell-checking and proofreading of documents.

4) Conformance to HTML 2.0 or 3.0 DTDs (Document Type Definition)-avoid use of browser-specific tags.
5) ALT attribute for images $<\mathrm{IMG}\rangle$-for benefit of browsers without graphics capabilities.

\section{Recommended:}

1) Markup language that is readable by future (human) maintainers (e.g., liberal use of line breaks and white space in the source documents).

2) Check finished document with variety of browsers, both text (Lynx) \& graphical (Netscape, Mosaic, etc.).

3) High-level elements in every document $(<\mathrm{HTML}><\mathrm{HEAD}><\mathrm{BODY}>$ ).

4) Low-resolution thumbnail images in text, pointing to full-resolution external images.

5) Development in nonpublic directories only.

6) Test with primary user group. 

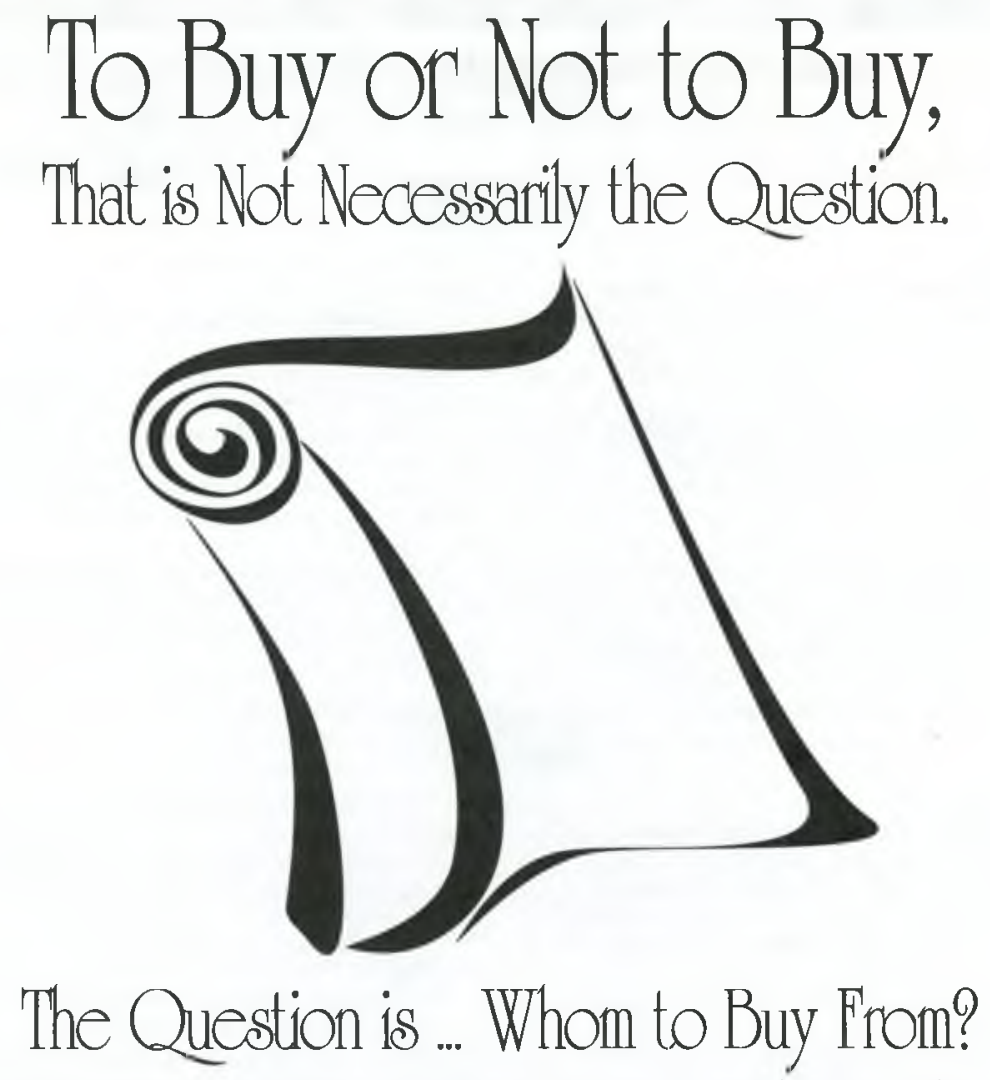

lacing an order should be simple and fast. With over fifty years of industry experience,
when you place an order with Brodart, you are placing an order with a leader in the
academic library market. Your order will be processed quickly and efficiently. You may place an order by mail or with our electronic ordering system. Orders are also accepted via fax or internet. If the title you have requested is not in our existing extensive inventory for immediate shipment, your titles will be ordered from the publisher immediately, regardless of quantity.

It is definitely not "nobler in the mind to suffer the slings and arrows" of ordering from other vendors. Let Brodart Academic Book Services assist you in your unending quest of where to buy. Call us today.

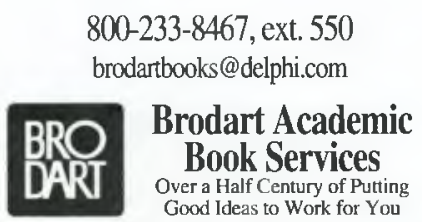

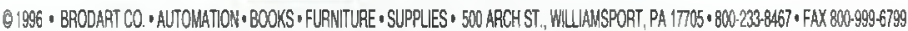
BROCART, LTD. 109 ROY BIVD., BRANTFORD, ONTARIO N3R 7KI • FAX 800-363-0483 